\title{
Local variants of mobile sustainable building assessment models: the marketization and constrained mutation of BREEAM ES
}

\author{
Please cite as: \\ Faulconbridge JR. Yalciner, S. (2015) Local variants of mobile sustainable building \\ assessment models: the marketization and constrained mutation of BREEAM ES. Global \\ Networks 15 (3) 360-378
}

\begin{abstract}
The globalization of sustainable building assessment models is now a familiar topic, as are related debates about the degrees of local sensitivity of such models. The contribution of this paper is to examine empirically the way marketization affects the mutation of models as they travel, and the implications of this for local sensitivity. By marketization we mean the effects when both a market for models emerges, and the adoption of a model acts as a means for an organization or city to gain competitive advantage over rivals. Using the case of one sustainable building assessment model, the Building Research Establishment Environmental Assessment Model (BREEAM), and its movement from the UK to Spain and transformation into BREEAM ES, the paper reveals the important ways that marketization can constrain mutation. Using Callon's ideas about translation, we show that the model was translated in a way designed to minimize adaptations to local context in order to maximise the comparability of buildings assessed using BREEAM ES with building assessed using other variants of the BREEAM model. This suggests, we claim, that marketization is a significant reason for the outcomes of the mobility of BREEAM being the opposite of that observed in many previous studies where a model's name stays the same but its content and the practice of implementation varies.
\end{abstract}

Keywords: BREEAM, globalization, sustainable building, marketization 


\section{Introduction}

The globalization of knowledge and practice relating to buildings is now a familiar topic. For example, from the steel frame building and concrete technology (Cody 2003), to the bungalow (King 1984), there is a well-documented tendency for design-types to travel. There are also welldocumented concerns about the local impacts on vernacular architecture of such mobility (Moore 2013). Most recently such debates have honed in on questions of sustainable building design. Starting from the position that sustainable design challenges and solutions are 'plural' and context specific (Guy and Moore 2007), studies have questioned the desirability of the global circulation of either sustainable design (Cole and Lorch 2003; Faulconbridge 2013) or assessment models (Cole and Valdebenito 2013; Faulconbridge 2015). This paper considers the mobility of sustainable assessment models in particular. Here, the main controversy relates to the potential for local adaptation, with some identifying opportunities for local variants of models to emerge (Cidell and Beata 2009), but others arguing that high degrees of context insensitivity result from the use of mobile models (Schweber 2013).

The contribution of this paper is to explain how the insensitivity identified in some literatures (see also Cole and Valdebenito 2013; Sev 2011; Wallhagen and Glaumann 2011) emerges, and results from the imperatives underlying the globalization of assessment models. It examines empirically and theoretically the way one global sustainable building assessment model - the Building Research Establishment Environmental Assessment Model (BREEAM) - had its mutation restricted as it travelled to Spain, thus reducing the extent to which local design practices and needs could be responded to sensitively. Mutation is used to refer to a situation in which models "are not, after all, merely being transferred over space; their form and their effects are transformed by these journeys" (Peck 2011: 793). In particular, by examining how BREEAM travelled to Spain and became BREEAM ES (the ES standing for España), the paper reveals the important ways that marketization can, in the case of assessment models, constrain the transformations highlighted by the idea of mutation. By marketization we mean the effects when both a market for models emerges, and when the adoption of a model acts as a means for an organization or city to gain competitive advantage over rivals (c.f., Peck and Tickell 2002; McCann 2013). Theoretically this is of significance as it reveals that under conditions of marketization, the translation processes that others have suggested lead to mutations can also restrict mutation. It is shown how an analysis informed by Callon's (1986) characterisation of translation as involving problematization, interessement, enrolment, and mobilization can reveal the reasons for restricted mutation and a paradox in the case of BREEAM that whilst the label of the model changed, the degree of change in terms of the content of the 
model was constrained, this being the opposite of the situation commonly observed in previous studies (e.g., Boxenbaum 2006; Czarniawska and Sevón 2005). The paradox is characterised here as a case of isopraxism rather than isomorphism, the latter generating pressure only to adopt the model (and its title), the former creating pressure to adopt practices of implementation (Erlingsdóttir and Lindberg 2005). The paper is, therefore, important because it reveals how mobile sustainable building assessment models such as BREEAM potentially become insensitive to local challenges and practices due to pressures of marketization, even if this was not the intention of those mobilizing the model.

The rest of the paper proceeds over five further sections. The next section reviews existing theorizations of mobility and mutation and outlines the way ideas about translation frame this paper's analysis. The BREEAM model is then introduced, before the way it was mobilised and became BREEAM ES in Spain is considered. The effects of marketization on this mobility are then analysed, before the concluding section reflects on the insights gained from the analysis.

\section{Mutating models}

In both literatures on global building assessment models, and wider social science studies of mobile models, an important stream of work has sought to counter tendencies to assume that globalization equals processes of diffusion. For instance, literature on mobile policy models concludes that "Even the "same" policies tend to be associated with different effects in different places, by virtue of their embeddedness in, and interactions with, local economic, social, and institutional environments" (Peck and Theodore, 2010a: 173). Often described as mutation (McCann 2011; Peck 2011; Quark 2013), the outcome of globalization is, according to such literatures, the reproduction rather than replication of models in different institutional contexts. Czarniawska and Sevón (2005) thus suggest that it is only the name of a global model that remains consistent as it travels, the meaning, content and impacts all varying from place-to-place.

Studies have accounted for mutation in a range of ways. Boxenbaum (2006) suggests the frame of interpretation will vary from place-to-place, and hence the meanings associated with a model and promoted to potential adopters need to be changed if mobilization is to succeed. McCann (2011) associates this type of mutation with the effects of the story telling used to mobilize models. Eick (2012) draws attention to the way the specifics of the institutional (regulatory, normative and cultural) environment of a place renders a mobile model more or less implementable, changes being made when institutional differences prevent a model being adopted in a form that 
exists elsewhere (see also Peck and Theodore 2010b). For Faulconbridge (2013), the outcome of mobility is, therefore, often a bricolage process through which a model is made to work in a particular local context.

Theoretically, such mutation has been conceptualised through work on processes of translation. Drawing on ideas from actor-network theory, translation is understood as a process by which the successful globalization of a model is assured (Alcouffe et al. 2008). Callon (1986) defined translation as involving processes of: problematization - relevant here as it relates to convincing others that the model in question is a solution to a recognised problem, this making the model indispensable; interessement - gaining the interest of different actors and building connections to the model as a result; enrolment - forging alliances with others who play interrelated roles in moving a model; and mobilization - monitoring to ensure the desired outcome is achieved. Those studying mutation have drawn attention to how during translation any model evolves as, in particular, problematization and interessement require concessions to be made to local context (Czarniawska and Sevón 2005). The question this paper addresses is how marketization influences processes of translation, the implications of this for mutation, and specifically relating to sustainable building assessment model, the implications of marketization for the local sensitivity of global models.

\section{Marketization and mutation}

For both those studying building assessment models, and parallel processes of knowledge and policy mobility, the market imperatives underlying mobility are all too apparent. Sklair (2006: 36) suggest that in the building industry the need "to keep people spending to maximize profits for the transnational corporations and their affiliates" underlies the globalization imperative. Peck and Theodore (2010b) highlight how mobile policy models provide 'fast' solutions. Such solutions are crucial in a context in which policy makers are encouraged to engage with the market. This engagement means both seeking cost savings by replicating policies implemented elsewhere, and gaining legitimacy and competitiveness for a city through the adoption of a global model.

Such market influences mean two important considerations need to be made when analysing mobile models. First, it is important to recognise that models become mobile as a result of the desire to sell solutions. As Peck (2011) argues, mobilisation involves selling rather than telling as interested parties seek to promote their models and profit from the advice given. Prince (2013) observes that this means consultants deliberately assemble models in ways that will sell around the world, with different groups competing against one-another in a way that creates a market for 
models. These 'sellable' models have particular market friendly characteristics which we explore further in our analysis below.

Second, those buying models do so with particular market related imperatives in mind. As Peck and Tickell (2002) observe, global models are appropriated as part of 'extrospective' efforts to become competitive. This involves adopting models that will allow comparison with (McCann 2013) and benchmarking against competitors (Larner and LeHeron, 2004) as organizations and cities seek advantage in global neoliberal markets. This second form of market influence dovetails with the first to create a situation in which both those 'pushing' and 'pulling', selling and buying global models do so in ways influenced by market priorities. These priorities need to be understood if their influences on translation are to be revealed and the implications for mutation explored. In particular, the double movement of buyer and seller market priorities has the potential to lead in the translation process to approaches which result in either positive or negative outcomes for local sensitivity. The nature and consequences of such market imperatives are examined below in relation to the case of the translation processes associated with the production of BREEAM ES.

\section{The case of BREEAM ES}

BREEAM originates in the UK. It was initially developed by the Building Research Establishment (BRE) as a model to assess the sustainability of UK buildings, primarily in the commercial sector although recently it has been expanded into other domains including schools and communities. Here we focus on the original commercial version. BRE describes the BREEAM model as being:

"the standard for best practice in sustainable building design, construction and operation and has become one of the most comprehensive and widely recognised measures of a building's environmental performance. It encourages designers, clients and others to think about low carbon and low impact design, minimising the energy demands created by a building before considering energy efficiency and low carbon technologies" (BREEAM 2014a)

There is a large literature on the technical specifications of BREEAM and other similar models (see for instance Bunz et al. 2006). Here, we are less concerned with technical specificities given that our interest is in processes affecting mutation, and more with the effects of mobilization strategies on the potential for local sensitivity. To summarise (and necessarily simplify) the approach of BREEAM, we note three core features. First, the model sets performance criteria (with credits awarded for meeting the criteria) for things such as modelled energy and water consumption, waste produced in the construction process, and impact on local environment. Second, the model also awards credits 
for following 'best practices' in design and construction, and for the provision of certain forms of sustainable infrastructure within a building. For instance, a significant example in our case study relates to credits awarded for providing facilities for cyclists. Third, the model provides a rating for a building according to the number of credits scored. For BREEAM, this is a rating from 'Pass', through 'Good', 'Very Good', 'Excellent' and 'Outstanding'. Our focus here is, therefore, on the way mutation occurs in relation to the first two features, and the extent to which a BREEAM rating reflects locally sensitive sustainable building design.

BREEAM is widely recognised as being one of the first sustainable building assessment models, and from an early stage BRE embarked on a project to globalize the model. As Courtney (1997) notes in his review of the evolution of the BRE organization, a crucial motivation for this was the transformation of BRE from a government research institute into an independent foundation with a commercial arm (the profits from the commercial arm funding the foundation), and hence the need to generate revenues and profits from the selling nationally and internationally of the BREEAM model and other products. However, the rise of competitor schemes has led to BREEAM facing a battle for global competitiveness. Taking inspiration from the BREEAM model, green building councils and private organisations around the world have developed rival models. For instance, Green Star has been developed in Australia and LEED in the USA (for a review of different schemes, see Bunz et al. 2006). As we note below, in Spain VERDE is the local assessment model. BREEAM has had some success; by 2014 buildings in over 50 countries had adopted the model. BRE thus proclaims that "BREEAM is an internationally recognised brand across the world, setting the standard for sustainability in the built environment" (BREEAM 2014b). Nonetheless, the fact that BREEAM operates in a completive market in which building owners can choose from multiple models is significant in our analysis below as it is one of the axes of marketization that affects mutation as the model travels.

\section{BREEAM in Spain}

The BREEAM ES variant is one of several nationally specific schemes developed from the original UK BREEAM model. In the early stages of globalization, BREEAM was exported using what was labelled as an 'International' variant of the scheme, the ambition being that this would provide the "flexibility of recognising local best practice codes and standards" (BREEAM 2014c). As BREEAM won the battle to be the dominant model in several European countries, a series of more specific national schemes were spun-off from the International model, BREEAM ES being one such scheme (others existing for 
Germany, the Netherlands, Norway, Spain, Sweden, and Austria). To date, 134 buildings have been assessed using BREEAM ES, with 57 assessors in Spain providing the advice and assessments needed to gain a BREEAM rating (BREEAM ES 2014). The International scheme remains in place and is used in countries where a nationally specific variant has not been developed.

We unpack below the process through which BREEAM ES was produced. Initially, 24 semi structured interviews conducted in 2012 to unpack the motivation behind the globalisation of BREEAM International. Interviews were completed in the UK, Belgium, Spain and Turkey as part of the second author's PhD thesis and investigated how BREEAM International emerged and was used in various contexts. The development of the BREEAM ES model, which started in 2010 and concluded with the launch of the first BREEAM ES manual in mid-2011, provided an opportunity to focus on the process of producing a national variant - insight gained into this being the focus of this paper. In the analysis below we, therefore, restrict our focus to the time (2010-2011) and processes associated with the making of the first BREEAM ES manual, and do not consider the model 'in use' in the design and construction of buildings since its launch in mid-2011. As such, our analysis is of the socio-economic processes affecting the making of the first BREEAM ES manual, this manual defining the assessment criteria used, the technical mutations enabled or prevented, and the implications for sensitivity to the context of the Spanish built environment. As a result, in the analysis below, we use a sub-set of interviews completed that relate directly to the making of BREEAM ES. Eight interviews are used, these being completed with: three BREEAM executives (two BRE Group executives and one from the partner organisation responsible for BREEAM ES), and five 'green building professionals' in Spain (four of them being assessors who actively took part in the process of producing the BREEAM ES manual, the others being a Spanish architect who had direct experience of the differences between BREEAM International and new ES variant). As such, we present insights from a limited number of key informants, but these are actors who played a central role in producing and could provide crucial insights into the first BREEAM ES manual. The interview schedule focused on the pitfalls and advantages of adapting a global assessment tool, how the process of adaptation occurred, and the outcomes in terms of mutations and implications for those involved in BREEAM ES assessed building projects. Interviews lasted between 60 to 90 minutes, were all recorded and transcribed. All interviews were completed in English. 


\section{The mobility of BREEAM to Spain}

Moving BREEAM to Spain through the production of BREEAM ES was a multi-actor process. BRE was heavily involved in the process. As we note below, this was primarily to ensure the imperatives that marketization imposed on the process of producing BREEAM ES were recognised. However, BRE's involvement was also a result of the organisation's belief that it had valuable expertise gained from developing BREEAM in the UK and latterly BREEAM International that could be reused in other countries. As one BRE Group executive noted:

"We [BREEAM] looked at what was working and not working. We have gone through a lot of negative stages in UK while improving our system, and our efforts can put other countries that are behind further faster than they could achieve on their own".

BRE could not, however, act alone to produce the BREEAM ES model. As is the case for all of the national BREEAM variants, a local partner organisation was enrolled to facilitate the movement of BREEAM into Spain. In the case of BREEAM ES this was the Instituto Technológico de Galicia - known as ITG for short. ITG had the task, under the supervision of BRE, of producing the BREEAM ES manual and supporting infrastructure. At one level, and relevant to questions of mutation, ITG played a key role in identifying changes needed to make the model applicability to the host country context, in this case Spain. This very much suggests that BRE recognised the need for mutation to be one outcome of the translation process. As a BRE Group executive noted:

"The construction process shows difference in relation to the changing market, culture, regulations, and materials in that particular location regardless the primary purposes of the building. If you make a core on what parameters make a building good, then all the cultural and local differences may shape the rest of the manual without interrupting the core. BREEAM manual designed with a common technical heart (approximately $60 \%$ of the whole manual) and this core is valid to be applied globally".

At another level, ITG had an important role in gaining legitimacy for BREEAM ES in Spain. One of the distinctive features of sustainable building assessment models is the way their success is built upon support from planning officials, building developers, and occupiers. For example, existing studies show that significant legitimacy is gained when credit is given as part of the planning approval process to a building assessed using a model such as BREEAM (Cole 2005). As a result, ITG had an important role in the process of problematization, i.e., ensuring BREEAM ES was recognised and valued by relevant actors in Spain as a solution to a sustainability problem. As an ITG representative 
noted, "If the authorities don't like the tool they won't use it, so we have to have a dialogue with them."

In addition, one further group of actors was involved in the translation process. We call this group 'green building professionals'. This group is comprised of individuals especially interested in sustainable design who are drawn from professions traditionally associated with buildings architects, building service engineers, quantity surveyors etc. In addition, some new actors are included in this group who have emerged in tandem with the rise of interest in 'green' buildings and models such as BREEAM. These include sustainability consultants and most importantly the assessors who determine the BREEAM rating of a building. These new actors are now important intermediaries and have a significant influence over the building designs ultimately adopted, even though models such as BREEAM are not supposed to be design tools (Schweber 2013). They further support problematization, providing the means to transform a model such as BREEAM into something building owners recognise and can use, this relating in particular to providing technical specifications for buildings, construction materials, and services provision. BRE thus enrolled 'green building professionals' by consulting with them widely during the process of producing BREEAM ES, and then providing extensive training on the use of the BREEAM ES model. As an ITG representative noted, "Assessor trainings are carried out within BREEAM ES now. Main BREEAM is still controlling BREEAM ES of course".

The comment about BRE controlling the training, which is consistent with the story below of BRE controlling the overall process of producing BREEAM ES, is indicative of the forms of mobilization used in the translation process. ITG was enrolled as a hired ally in the translation process, and 'green building professionals' were enrolled through the incentives provided by the profits they could make from clients once trained, certified and capable of using BREEAM ES. But, at all times, BRE deployed tactics of mobilization to ensure the competitiveness of the model was not threatened, this implying a direct and, as we describe below, interventionist role in the production of BREEAM ES.

\section{Mutation}

The role of ITG at its simplest related to linguistic issues - reproducing manuals in Spanish. However, it was recognised from the outset, thanks to experience of implementing BREEAM International in Spain, that some degree of content change would be necessary and that ITG would have a role in this. As a BRE Group executive outlined: 
"We look at the metrics such as regulations, materials, and techniques in the UK and Spain to compare and to understand what caused the buildings in these two countries to be different. We cannot credit buildings in other countries based on our UK knowledge, otherwise many of them will keep failing and this will de-encourage them".

As such, ITG had an important role in making BREEAM ES a model that would have traction in Spain. After all, problematization would only be possible if the model appeared to address Spanish sustainability concerns. 'Green building professionals' also had a similar role. This related to the transforming of the performance criteria set by BREEAM ES into specifications for building design, construction materials, and service provision that are implementable in Spain, otherwise those commissioning buildings would not see the model as useable. For example, a BRE Group representative observed the following about the role of BREEAM ES assessors:

"This is where innovation comes in. There are multiple ways of gaining credit and it is up to the assessor and developer to try. Our ideas are giving space people to innovate. We drive innovation and change"

On the surface, then, the enrolment of ITG and 'green building professionals' and their centrality in problematization created significant potential for change as BREEAM became BREEAM ES. However, in order to understand the potential for mutation it is also essential to consider the effects of mobilization, Callon (1986) describing this as a means of control in the translation process. In this case mobilization is important because, despite the rhetoric of the need for adaptation to local context and innovation, the process of moving BREEAM into Spain actually involved significant restrictions being placed on change. Indeed, it emerged from interviews that both ITG and 'green building professionals' had a number of reservations in this regard. For example, an ITG representative and a BREEAM assessor who was involved in the development of BREEAM ES, respectively noted that:

"BRE wants to keep their methodology same in all the countries, so only small revisions allowed for BREEAM ES adaptation. BRE kept the parameters, issues and credits same to keep their methodologies same"

"The manual is created such in a way to cover all types of buildings and locations. We have given our ideas during the adaptation process but we have been told that it cannot change. They didn't consider much. They want the all the buildings to have similar assessment method" 
These comments demonstrate the desire of BRE to minimise change in the substantive content of BREEAM ES compared to BREEAM and its International version. Indeed, it was notable in interviews that BRE's agenda was repeatedly represented as one that was sensitive to local sustainability needs and practices, but not at the expense of a 'best practice' agenda, BREEAM being seen as a best practice that brings benefits to other countries when imported. Exemplifying this tendency, a BRE Group executive suggested that:

"We prefer to make it accessible and achievable. We [BRE] want from our partners all around the world to develop that knowledge locally. We [BRE] are not trying to tell any organisation what to do in their own location but we are producing knowledge and allowing this knowledge to transfer between countries and continents (emphasis added)"

The result of this was control of the activities of ITG by BRE, something enabled by BRE's enrolment of ITG as a contracted service provider. Hence, as one interviewee familiar with ITG's work noted, it involved:

'negotiations between the two sides. We examined the categories and sent our work to BRE Group UK. Our demands reviewed by BRE Group however most of our suggestions rejected.' Indeed, an ITG representative even went as far as saying "Many issues [in non-UK manuals] are directly copied from BREEAM UK". As such, the contractual relationship prevented ITG making changes BRE did not approve.

For 'green building professionals' mobilization controls took a subtly different form. The training programmes created as part of the process of creating BREEAM ES were the key means by which green building professionals encountered the final model. By monitoring the content of training and ensuring it promoted approaches favoured by the organization, BRE was able to control the understanding that 'green building professionals' developed of sustainability and the BREEAM model. A notable effect of this for our interviewees was the way BREEAM ES was presented as a, or perhaps even the model of building sustainability. In particular, questions about what sustainability means or how it can be achieved were closed down. As an architect in Spain noted:

"I have been trained by BREEAM so I am aware of what is does however trying to apply sustainability measures without really knowing what it means is difficult. People involved in the industry should have at least the basis of the sustainable building information"

Underlying this concern was a sense, as the interviewee quoted earlier also suggested, that whilst "Assessor trainings are carried out within BREEAM ES now, BRE is still controlling BREEAM ES of 
course" (Spanish 'green building professional'). As such, the suggestion was that, in Callon's (1986) terms, training was being used to control problematization and to minimise adaptations.

Problematization in this sense refers to how the problem being addressed is framed and, in particular, how a model, in this case BREEAM ES, is presented as a solution to or 'obligatory passage point' in this problem. Control over 'green building professionals' was, then, maintained through control of the definitions of and solutions for sustainability presented at training events and hence how they understood BREEAM ES as a solution to these problems. As a local architect put it:

"The fame of the codes prevented to question their content and 'wisdom' on 'sustainability'”.

We reflect further on how this was achieved below, given that it acted as a means of governance through which the 'best practice' claims of BREEAM were established. When combined with control of ITG, the governance of 'green building professionals' meant that, as a BREEAM assessor in Spain put it, "BRE Global was involved in the adaptation process, which in a way they did not let the tool to become too Spanish". As another assessor put it, "There are some differences between BREEAM International and ES but...very little re-calculations occurred in the credit arrangements". The fact that translation occurred in the context of pressures of marketization helps explain why such a situation arose.

\section{Marketization, interessement, and the priorities of translation}

The theoretical starting point for understanding why BRE controlled so carefully the translation of BREEAM into BREEAM ES is a discussion of Interessement in the translation process - i.e., the process of generating shared interests between those selling and buying a mobile model to ensure mobility occurs. To understand this, it is important to begin by reiterating, as was noted above, that as an organisation BRE was transformed in the late 1990s as it became independent from government and developed a for-profit arm and agenda. One consequence of this was (and still is) the commercial imperative that the BREEAM model delivers a constant revenue stream. Hence, being internationally recognised and adopted is crucial. As a local Spanish architect noted:

"BREEAM International was born to meet the demand of 'green building assessment' in Europe. BRE considered their fame and money at the first place and released an international version" 
Control of the translation of BREEAM was thus driven by BRE's need to act in ways that are responsive to both local and other global competitor models. This has been necessary because, as the same Spanish architect described:

"There was an obvious gap in the sector and BREEAM clearly filled in temporarily. As the green building assessment tools sector developed, marketing got competitive."

In the Spanish context local competition came from the VERDE model operated by the Green Buildings Council España. Global competition cames principally from the LEED model, the US Green Building Council which owns this model having similar globalisation ambitions and priorities to BRE. As a 'green building professional' in Spain described the implications of these two forms of competition:

"BREEAM has the UK market and they are too relaxed on other markets. BREEAM is not doing good in marketing, so I am sceptical whether BREEAM ES would be permanent tool in Spain or not".

As BREEAM ES operates in a market for models in which clients can choose the model they consider most competitive, an imperative exists to control how the model is translated so that key features that provide competitive advantage in the market are not undermined. This has meant, in particular, emphasising the way BREEAM ES allows comparability and international profile, those buying BREEAM ES often being motivated by a desire to be able benchmark their building against others worldwide. As such, adopting BREEAM ES, because of its international profile and comparability, provides a way for an organization or city to gain competitive advantage over rivals, so long as the building in question is assessed as being on a par or better that 'rivals' elsewhere. Hence as an ITG representative noted:

"The manual is created such in a way to cover all types of buildings and locations. We have given our ideas during the adaptation process but we have been told that it cannot change. They didn't consider much. They want all the buildings to have similar assessment".

As such, the translation process was managed to ensure that the international identity and comparability of BREEAM was not lost, this providing competitive advantage compared to VERDE, and being something LEED similarly offers. Interessement thus meant aligning the interests of BRE who were selling the model with those of the building owners buying BREEAM assessments in Spain, this being achieved by BRE prioritizing in the production of BREEAM ES outcomes aligned with building owners' desires for international comparability and profile. Representative of this, and identifying an issue that BRE arguably failed to address, is the following comment from a 'green 
building professional' in Spain which honed in on the plaque that a BREEAM accredited building can display:

“BREEAM Plaque's is simple and ugly. LEED plaques is more showy and that what clients want"

The focus on the plaque is indicative of how international recognition and the symbolic nature of a BREEAM rating are crucial drivers in clients choosing (or not because the plaque is not showy enough) BREEAM ES. The international dimension to this competitiveness is further revealed by how, as two BREEAM assessors in Spain independently noted:

"VERDE is a recent tool produced by the green building council in Spain. The tool did not attract many developers due to being only local"

"Spain has a local tool called VERDE, which means green in Spanish but it is not well developed, and still too young. Even it was well developed we wouldn't consider using it in the future due to being local and not known in global context"

In particular, the adoption of BREEAM ES provides for companies and cities the possibility of benchmarking their buildings, and symbolically their corporate or city identity, with international competitors, this enhancing international visibility. As others have noted (Larner and LeHeron 2004; McCann 2011; Peck and Tickell 2002), such a focus on benchmarking and comparison is indicative of the way those buying and selling mobile models are affected by market imperatives. Selection of a model is influenced by market logics such as relative competitiveness of the BREEAM ES model itself and potential competitive benefits gained by the building designer/owner/occupier from a BREEAM assessment, and the comparability and commensurability generated. As two 'green building professionals' in Spain noted:

"The demand for BREEAM grew when Sonia, an important retail promoter in Europe, used BREEAM to assess a shopping centre. That has defined the norm for shopping centre builders; to have BREEAM assessment. All shopping centre developer companies wanted to use the same tool to compare"

"BREEAM International in global level, which would give its customers, to the building developers in general, the option to compare buildings all around the world under the same brand. The comparability factor is the focal point of interest from building developers' perspective" 
As a result, not only was the BREEAM ES model pulled into Spain by desiring clients who wanted to benefit from its international profile and comparability, but issues of interessement meant BRE felt compelled to use the mobilization tactics described above to constrain changes so that the international comparability of a BREEAM ES building with a building rated using another variant of BREEAM was maintained. As an ITG representative described:

"BREEAM ES is the adapted and more practical version of BREEAM International to Spain. However, the clients are interested in the international version. Clients are the building developers most of the time and comparison is an important aspect for them"

Indeed, perhaps somewhat cynically, some buyers encouraged limited mutation as they feared that BREEAM ES would develop more detailed assessments and, therefore, that assessed buildings would not only lack comparability but would receive a lower rating than a building assessed using the International scheme. As such, clients hoped that the shortcomings of a model that underwent limited mutation could be exploited. As a BREEAM assessor in Spain noted:

"Some clients are afraid that BREEAM ES version will make more detailed assessment and therefore the building will receive a lower rating"

In Callon's (1986) terms, we see then in the case of BREEAM ES how the effects of marketization led to particular priorities in the process of interessement which created constraints on mutation. As a result, translation became a tool to enable mobility through a restricted set of necessary and unavoidable adaptations to local context, rather than being a tool for producing a model truly sensitive to local design priorities and practices.

\section{The contradictions of constrained mutation}

The simplest effect of the pressures of marketization described above was a translation process focussed more on language than content. This created immediate challenges because those at ITG working on the production of BREEAM ES recognised that multi-level changes were needed if the model was to genuinely take account of Spanish sustainability challenges and solutions. As one ITG representative put it:

"ITG proposed revisions in two levels after a set of considerations. The first level was to evaluate conflicting issues with the Spanish law and regulations. Second level was the revision and adaptation of the issues to the Spain context. This includes amendments of issues which are not suitable with Spain and Spanish way of living" 
Ultimately, changes did occur in relation to the first level. Adaptations were made to take into account Spanish building codes, many of these changes being climate related; Spain on the whole having higher average temperatures and lower rainfall that the UK. Hence water preservation and the prevention of over-heating are more tightly regulated in Spain. One BREEAM assessor in Spain noted that "Water category is only 9\% in the assessment but water is a more important issue for Spain and in Spanish regulations", whilst another assessor highlighted the need to consider the "heat island effect, it is required in Spain". Indeed, it is possible to observe a layering process in the BREEAM ES manual whereby the BREEAM International criteria are adopted and additional criteria added to reflect particular Spanish regulatory concerns. Hence the main differences between the assessment categories in BREEAM International and BREEAM ES emerge from the addition of the following four sub-categories: in relation to health and wellbeing, criteria Hea 08 'Sustainable water treatment for swimming pools'; in relation to waste, Wst 03 'Urban waste management' and Wst 04 'Horizontal wall cladding'; and in relation land use and ecology, LE 06 'Erosion control'.

Adaptation was, then, made in relation to regulations, this being unavoidable as failure to do so would have led to penalties such as fines. But, adaptation at the second level identified by ITG was inhibited. Building design and construction norms, cultures, practices and associated knowledge bases and skillsets were not fully responded to, making the appropriateness of BREEAM ES questionable for many of our interviewees. On one hand, this raised concerns in relation to pragmatic issues such as whether it was possible to comply with the demands of the model. For instance, one BREEAM assessor in Spain noted how, from his perspective:

"UK is very bureaucratic so it is expected from us to be like them. However, it is very difficult to try to get everyone involved in the process to be as bureaucratic as it is expected by UK, such as the contractor, therefore the duration of the process gets longer and longer"

Another assessor described how:

"Contractors had a lot difficulty in applying BREEAM requirements. Spanish contractors are not used to follow a list of to---dos, like the ones in UK"

On the other hand, concerns existed about the sustainability fixes that were indirectly promoted by BREEAM ES through the things given credit for, and in turn what was not credited. A good example of this relates to the credits given for cycling facilities. The importance of such credits in gaining one of the higher ratings created pressure to provide facilities in the same way as in the UK. In doing so, the absence of the wider infrastructure for cycling, needed to make such facilities effective, was 
ignored. As one 'green building professional' actively involved in producing the BREEAM ES manual noted:

"During the adaptation of the tool, we (assessors) agree that installing cycle racks and building showers in the buildings is crazy and it will not work in Spain. Cycling is not a common practice in Spain...Therefore, we asked BREEAM either to reduce the credit or to replace it with anything else. However, they insisted on keeping the cycling credit as it is. They (BREEAM) think bicycle racks will encourage the public. We have been told "If we (BREEAM) keep it as it as, and you (BREEAM ES) implement this, a building with cycle racks will be the engine to the whole system". There is no cycling facility, no infrastructure, and lack of proper lanes in Spain. Upgrading the required facilities totally depends on the public authority"

As a result, significant amounts of embodied carbon were expended on cycling infrastructures when there is little chance they will be used. As another 'green building professional' elaborated:

"We are not a country with a high demand to bicycle use. According to BREEAM tool, one cycle rack should be placed per ten square meters. A shopping mall is around 20,000 square meters and in that case the number of bicycle rack to be mounted is enormous"

For interviewees this led to a sense that "National best practices are advised to be used in some of the parameters but if there is no national best practice then UK national best practice will be used". From the perspective of BRE, such an approach is justified by the 'best practice' agenda described previously. When there was an absence of clear guidelines or norms and cultures that promote sustainability, BREEAM ES was treated as a means of introducing new 'best practices'. As one BRE Group executive suggested, "BREEAM is all about market transformation" Another BRE Group executive observed that:

"Starting from scratch [to design an assessment tool] is very difficult. It involves massive amount of engagement process. For instance, BREEAM communities took months and months and months engaging with architects, industry, client, local authority, and developers. We [BREEAM] know how to create good standards so what we do internationally is knowledge transfer on best practice"

Of course, such claims cannot prevent cynicism and concerns on the part of some of the 'green building professionals' and other stakeholders in Spain, given the apparently limited adaptation of BREEAM ES to local conditions. However, in line with the need to respond to pressures of marketization, BRE managed such issues through a further form of mobilization control. By designing 
the model in a way that black-boxed many of its components, it was made difficult to challenge and further adapt the model. For instance, the tracker spreadsheets used to list the criteria assessed by the BREEAM model constrain both by writing some things out but also by rendering invisible the underlying rationale behind the performance criteria set (Schweber 2013). Similarly, BRE also sets tight parameters around the materials that can be used and which are defined as delivering sustainability. The materials used are controlled through the requirement for data relating to their performance (for example in terms of insulation values). However, the tests required are not recognised and completed in many places outside of the UK. Thus it is common outside of the UK to be unable to source local materials that have been assessed in the required way. As one BREEAM assessor in Spain noted:

"what is used in construction varies internationally, but BREEAM demands products with very particular specifications, which may not be appropriate or available in other non-UK contexts. Local material usage and traditional building techniques, in other terms, vernacular architecture is replaced with globally recognised contemporary design style since the 20th century and similarly the interest paid to construct 'modern looking building'. The main considerations of design has been replaced by such global certifications"

BRE is willing to listen to challenges to the model and to problems with it. As one BRE Group executive noted:

"Anything (any issues) we put there (manual) is to increase the sustainability, reduce emissions. Some of the parameters and issues might be culturally different [....] We value scientific evidence. Show me the research to change anything, including anything to do with culture and we would change it."

However, producing the data that BRE considers to be scientific evidence is difficult. As such, and reflecting Prince's (2013) observation that those mobilising models use quantification to obscure difference and render models stable, despite the recognised contradictions that exist in BREEAM ES it is hard to challenge and secure adaptations. Consequently, when assessing a building using BREEAM ES, often the only option is to use materials listed in BRE's Green Book. The materials listed here are frequently UK or Northern European in origin, because of BREEAM's birthplace, and may not necessarily be best suited to the climates of countries such as Spain. As one BREEAM assessor in Spain noted, this means:

"the material category in general is challenging us in the Spanish market. Green book live is an advantage in UK but we don't have the materials stated in the guide here in Spain. 
Additionally, only few materials in Spain have the life cycle analysis. In UK you can choose materials, here we can't"

The net result was that interviewees commonly suggested that BREEAM ES has a Spanish name but is still a British assessment system, the opposite to what others have documented as the outcome of the translation process, the name staying the same but content changing in cases reported elsewhere (e.g. Boxenbaum 2006; Czarniawska and Sevón 2005; Ward 2011). Indeed, the effect of BREEAM ES is to create what Erlingsdóttir and Lindberg (2005: 58) describe as isopraxism. As a form of pressure for compliance this involves new practices being forced upon adopters so that their practices conform to the standards of the model. Isopraxism differs from isomorphism in that the latter generates pressure only to adopt the model (and its title), with practices of implementation being less controlled. The pressures of isopraxism associated with BREEAM ES result from the marketization constraints outlined in this paper and, as the discussion above suggests, raise significant questions about the ability of BREEAM ES to promote locally sensitive sustainable building design.

\section{Conclusions}

In this paper we examine the way marketization affects the mobility of the BREEAM sustainable building assessment model and mutation as part of movement to Spain. We show that mutation was constrained due to pressures of marketization and the need to make BREEAM ES an internationally competitive and comparable model. This ensures the owners of assessed building gain international recognition and benchmarking advantages. Our story of the mobility of the BREEAM model makes three important contributions to existing literatures.

First, the story explains what others have observed noted (Cole and Lorch, 2003; Cole and Valdebenito 2013; Guy and Moore 2007; Sev 2011; Wallhagen and Glaumann 2011): i.e., that mobile sustainable building assessment models tend to be insensitive to local sustainability problems and solutions. We show that insensitivity is determined not just by the intrinsic technical characteristics of the model in question but also by processes of mobility. In the case of BREEAM this is illustrated by the way BRE's espoused recognition of the need for local sensitivity was undermined by actions driven by pressures of marketization. As such, it is the way a model is sold (Peck 2011) by those mobilising it that determines the way mutation occurs as part of the journey. BRE, like the consultants studied by Prince (2013), sought to control processes of mobility in ways that closedown possibilities for mutation; this acting in a governmental sense to control the understandings of 
sustainability developed by green building professionals, and black box the model so that challenges to its legitimacy are minimised. This implies that more attention needs to be paid to the specific techniques deployed to develop such control. Here we have sought to unpack these techniques by revealing the effects of the pressures of marketization on the translation processes discussed by Callon (1986). We show that processes of interessement seek to respond to the pressures of marketization, and result in those enrolled to enable mobility being constrained in the changes they can make and the problematizations they help support, this being achieved through technologies of control associated with mobilization. There is, though, clearly more work to be done to unravel the practices and technologies of power used in forms of mobilization control and their relationships to questions of marketization, this being crucial given the neoliberal market context for all forms of model mobility (Peck and Theodore 2010b).

Secondly, the case reported here also advances our understanding of the significance of comparability (McCann 2013), and benchmarking (Larner and LeHeron 2004). As the story of marketization reveals, it is impossible to understand the mobility of policy, assessment or any other models outside of the context of global neoliberal logics which in various ways promote market based and 'extrospective' practices (Peck and Theodore, 2010b; Peck and Tickell 2002). For BREEAM $E S$, one significant outcome of this was a focus on international profile and competitive advantage, this focus being responded to by making BREEAM ES as consistent as possible with the BREEAM models used elsewhere in the world. Those mobilising BREEAM could not ignore the role of comparability and benchmarking in making the model competitive, and this explains why mutation during mobility might be less than expected. In the case of BREEAM ES this resulted in a change of name and some adaptations to take account of regulatory issues, but minimal changes in light of norms and cultures.

Thirdly, and related to the second point, whilst there are many parallels to the other kinds of models reported in the existing literature on mobility, the story of BREEAM ES reveals the way that assessment models, and the pressures of marketization they face, generate unique considerations as far as mutation is concerned. As a result of the way that assessment models focus on defined performance standards, and international comparability of performance standards is crucial to fulfil the international benchmarking and profile building sought by those adopting such models, the process of importing models into new contexts is concerned with not only maintaining the label/name of the model, but also the practices promoted. In the case of BREEAM ES this meant that adoption of the model implied the adoption of particular design practices, with in part materials also getting defined by the model. This suggests assessment models generate pressures of isopraxism 
and not just isomorphism (Erlingsdóttir and Lindberg 2005). It would, seem, therefore that there are further important questions which need to be explored in relation to the way, for different kinds of models, mutation occurs at different levels. The analysis here suggests mutation can be at the level of name or practices, but it would be worth exploring further whether these two categories can be further disaggregated (for example, does the practice category need to be broken down into different dimensions such as design, implementation, assessment etc). The extent to which such questions apply and answers vary between varieties of mobile model, promoted by consultants, NGOs, the media, as well as varieties of business models, relating to corporate social responsibility, human resource management and other issues, would also be worth exploring.

In relation to the specific case of BREEAM ES, it would be useful to consider further the different levels of mutation by examining how the model has evolved since 2011/12 when this study was completed. Since the original manual was produced updated versions have been developed, and it would, therefore, be insightful to consider the extent to which degrees or levels of mutation have changed and how this relates to marketization pressures. Potentially, greater local sensitivity may have been developed in response to the kinds of critiques outlined in the analysis above. The analysis here presents, then, a number of important insights into how contextual insensitivity can emerge that can be used to track the mutation of mobile models over space and time.

\section{Acknowledgements}

\section{References}

Alcouffe, S., Berland, N. \& Levant, Y. (2008) 'Actor-networks and the diffusion of management accounting innovations: a comparative study', Management Accounting Research, 19, 1-17.

Bathelt, H. \& Glückler, J. (2014) 'Institutional change in economic geography', Progress in Human Geography, 38, 340-63.

Boxenbaum, E. (2006) 'Lost in Translation The Making of Danish Diversity Management', American Behavioral Scientist, 49, 939-48.

Bunz, K. R., Henze, G. P. \& Tiller, D. K. (2006) 'Survey of sustainable building design practices in North America, Europe, and Asia', Journal of architectural engineering, 12, 33-62.

Callon, M. (1986) 'Some Elements of Sociology of Translation: Domestication of the Scallops and the Fishermen of St. Brieuc Bay', In Law, J. (ed) Power, Action and Belief. London, Routledge \& Kegan Paul. 
Cidell, J. \& Beata, A. (2009) 'Spatial variation among green building certification categories: Does place matter?', Landscape and urban planning, 91, 142-51.

Cody, J. W. (2003) Exporting American Architecture, 1870-2000, London \& New York, Routledge.

Cole, R. J. (2005) 'Building environmental assessment methods: redefining intentions and roles', Building Research \& Information, 33, 455-67.

Cole, R. J. \& Lorch, R. (eds) (2003) Buidlings, culture and Environment. Informing local and global practices, Oxford, Blackwell.

Cole, R. J. \& Valdebenito, M. J. (2013) 'The importation of building environmental certification systems: international usages of BREEAM and LEED', Building Research \& Information, 41, 662-76.

Courtney, R. (1997) 'Building Research Establishment past, present and future', Building Research \& Information, 25, 285-91.

Czarniawska, B. \& Sevón, G. (2005) 'Translation is a vehicle, imitation its motor, fashion sits at the wheel', In Czarniawska, B. \& Sevón, G. (eds) Global ideas. Copenhagen, Copenhagen Business School Press.

Eick, V. (2012) 'The co-production of purified space: hybrid policing in German Business Improvement Districts', European urban and regional studies, 19, 121-36.

Faulconbridge, J. R. (2013) 'Mobile 'green'design knowledge: institutions, bricolage and the relational production of embedded sustainable building designs', Transactions of the Institute of British Geographers, 38, 339-53.

Faulconbridge, J. R. (2015) 'Mobilising sustainable building assessment models: agents, strategies and local effects', Area.

Guy, S. \& Moore, S. (2007) 'Sustainable Architecture and the Pluralist Imagination', Journal of Architectural Education, 60, 15-23.

King, A. (1984) The bungalow: the production of a global culture, Routledge/Thoemms Press.

Larner, W. \& Le Heron, R. (2004) 'Global benchmarking: participating 'at a distance' in the globalizing economy', In Larner, W. \& Walters, W. (eds) Global Governmentality: Governing International Spaces. London, Routledge.

Mccann, E. (2013) 'Policy boosterism, policy mobilities, and the extrospective city', Urban Geography, 34, 5-29.

Mccann, E. J. (2011) 'Urban policy mobilities and global circuits of knowledge: Toward a research agenda', Annals of the Association of American Geographers, 101, 107-30.

Moore, S. (2013) 'What's wrong with best practice? Questioning the typification of new urbanism', Urban Studies. 
Peck, J. (2011) 'Geographies of policy From transfer-diffusion to mobility-mutation', Progress in Human Geography, 35, 773-97.

Peck, J. \& Theodore, N. (2010a) 'Mobilizing policy: Models, methods, and mutations', Geoforum, 41, 169-74.

Peck, J. \& Theodore, N. (2010b) 'Recombinant workfare, across the Americas: Transnationalizing "fast" social policy ', Geoforum, 41, 195-208.

Peck, J. \& Tickell, A. (2002) 'The Urbanization of Neoliberalism: Theoretical Debates Neoliberalizing Space', Antipode, 34, 380-404.

Prince, R. (2013) 'Consultants and the global assemblage of culture and creativity', Transactions of the Institute of British Geographers.

Quark, A. A. (2013) 'Institutional mobility and mutation in the global capitalist system: a neoPolanyian analysis of a transnational cotton standards war, 1870-1945', Environment and Planning A, 45, 1588-604.

Schweber, L. (2013) 'The effect of BREEAM on clients and construction professionals', Building Research \& Information, 41, 129-45.

Sev, A. (2011) 'A comparative analysis of building environmental assessment tools and suggestions for regional adaptations', Civil Engineering and Environmental Systems, 28, 231-45.

Sklair, L. (2006) 'Iconic architecture and capitalist globalization', City, 10, 21-47.

Wallhagen, M. \& Glaumann, M. (2011) 'Design consequences of differences in building assessment tools: a case study', Building Research \& Information, 39, 16-33.

Ward, K. (2011) 'Policies in motion and in place: the case of business improvement districts ', In Mccann, E. \& Ward, K. (eds) Mobile urbanism: cities and policymaking in a global age. Minneapolis, University of Minnesota Press. 